\title{
ВЕЙВЛЕТ-АНАЛИЗ МНОГОЛЕТНЕЙ ДИНАМИКИ ЛОКАЛЬНОЙ ЧИСЛЕННО- СТИ ЛЕСНЫХ ПОЖАРОВ
}

\author{
Мазуркин П.М. ${ }^{1}$, Каткова Т.Е. $^{1}$ \\ ${ }^{I}$ ФГОУ ВПО «Поволжский государственный технологический университет Минобрнауки России», Йошкар- \\ Ола, Россия (424000, г. Йошкар-Ола, пл. Ленина, 3), e-mail: kaf_po@mail.ru
}

Проведен анализ волновыми уравнениями, имеющими переменные амплитуды и периоды колебательного возмущения, количества ежегодных лесных пожаров за период с 1963 по 2012 год на локальной территории Республики Марий Эл. Показаны импульсные функции резкого роста численности лесных пожаров, а также переходы от одного вейвлета к другому через изменения полупериода колебания количества. Доказано, что вейвлет-сигналы не зависят от цикла солнечной активности (эффекта А.Л. Чижевского) в среднем 11,3 года и цикла обращения ядра Солнца вокруг своей оси в среднем 22,4 года. Большинство вейвлетов зависит от поведения населения людей и уровня организации противопожарной профилактики в лесах. Высокоадекватные закономерности, полученные идентификацией устойчивых законов, позволяют создать прогнозную модель для разработки долгосрочных противопожарных мер при проведении ежегодной повторной идентификации модели по данным мониторинга за лесами.

Ключевые слова: лесные пожары, количество, динамика, вейвлеты, общая модель.

\section{WAVELET-ANALIZ OF LONG-TERM DYNAMICS LOCAL NUMBER OF FOREST FIRES}

\author{
Mazurkin P.M. ${ }^{1}$, Katkova T.E. ${ }^{1}$ \\ ${ }^{I}$ Volga State University of Technology, Ioshkar-Ola, Russia (424000, Ioshkar-Ola, Lenin Square, 3), e-mail: \\ kaf_po@mail.ru
}

The analysis by the wave equations having variable amplitudes and the periods of oscillatory indignation, number of annual forest fires from 1963 for 2012 years in the local territory of Mari El Republic is carried out. Pulse functions of sharp growth of number of forest fires, and also transitions from one wavelet to another through changes of a half-cycle of fluctuation of quantity are shown. It is proved that wavelet -signals don't depend on a cycle of solar activity (A.L.Chizhevsky's effect) on the average 11,3 years and a cycle of the address of a kernel of the Sun round its pivot-center on the average 22,4 years. The majority wavelets depends on behavior of the population of people and level of the organization of fire-prevention in the woods. The high-adequate regularities received by identification of steady laws, allow to create expected model for development of a long-term fire prevention when carrying out annual repeated identification of model according to monitoring behind the woods.

Keywords: forest fires, quantity, dynamics, wavelets, general model.

Введение. Территорию Республики Марий Эл (РМЭ) можно приять за локальную точку на карте Российской Федерации. Для неё климатические условия приняты постоянными, а леса занимают более 54\%. Следующими отличительными признаками этой точки являются малая плотность населения, компактная урбанизация, высокая экологичность территории.

Из-за экологических кризисов усиливается значение лесов в климатических технологиях и роль лесного хозяйства в динамике лесных пожаров, которые ныне сопоставимы с площадью лесов, вырубаемых для древесины. Большое количество лесных пожаров, огромные потери природных и антропогенных ценностей из-за них вызывают потребность в анализе, прогнозе и долгосрочных мерах по защите лесов. Для этого в статье предлагается методика выявления статистических закономерностей динамики численности лесных пожаров, позволяющая создать базу для ежегодного мониторинга и итерационного прогнозирования. 
Концепция моделирования и исходные данные. Информационную базу для анализа и выявления волновых функций составили официальные данные территориального органа Федеральной службы государственной статистики, Министерства лесного хозяйства по РМЭ.

Всплеск количества пожаров в лесах РМЭ в 2002 г. был, по-видимому, связан с циклом солнечной активности [1; 2]. Таким образом, максимумы 1972, 2002 и даже 2010 гг. численности лесных пожаров показывают наличие пока неизвестной математической зависимости.

Однако основной причиной возникновения лесных пожаров является неосторожное обращение с огнем населения и людей, работающих в лесу. От природных гроз за 10 лет возникло всего 5,8\% пожаров, но ими было погублено 28,4\% от поврежденной пожарами площади леса [10]. Поэтому солнечная радиация влияет на возгораемость лесных горючих материалов [7], но количество пожаров $N$ на 94,2\% зависит от человеческого фактора.

Поэтому в статье время $t$ (табл. 1) принимается за главную влияющую переменную. Относительно неё затем можно дать анализ динамики солнечной активности по числам Вольфа, и только после этого можно будет браться за изучение влияния чисел Вольфа на пожары.

Таблица 1 - Количество лесных пожаров на гослесфонде РМЭ (с учетом НП «Марий Чодра»)

\begin{tabular}{|c|c|c|c|c|c|c|c|c|c|c|c|c|c|c|c|}
\hline Год & $\begin{array}{c}\text { Время } \\
t, \text { лет }\end{array}$ & $\begin{array}{c}\text { Кол-во } \\
N, \text { шт. }\end{array}$ & Год & $\begin{array}{c}\text { Время } \\
t, \text { лет }\end{array}$ & $\begin{array}{c}\text { Кол-во } \\
N, \text { шт. }\end{array}$ & Год & $\begin{array}{c}\text { Время } \\
t, \text { лет }\end{array}$ & $\begin{array}{c}\text { Кол-во } \\
N, \text { шт. }\end{array}$ & Год & $\begin{array}{c}\text { Время } \\
t, \text { лет }\end{array}$ & $\begin{array}{c}\text { Кол-во } \\
N, \text { шт. }\end{array}$ & Год & $\begin{array}{c}\text { Время } \\
t, \text { лет }\end{array}$ & $\begin{array}{c}\text { Кол-во } \\
N, \text { шт. }\end{array}$ \\
\hline 1963 & 0 & 83 & 1973 & 10 & 84 & 1983 & 20 & 49 & 1993 & 30 & 142 & 2003 & 40 & 84 \\
\hline 1964 & 1 & 163 & 1974 & 11 & 88 & 1984 & 21 & 88 & 1994 & 31 & 91 & 2004 & 41 & 111 \\
\hline 1965 & 2 & 51 & 1975 & 12 & 162 & 1985 & 22 & 51 & 1995 & 32 & 233 & 2005 & 42 & 164 \\
\hline 1966 & 3 & 168 & 1976 & 13 & 18 & 1986 & 23 & 84 & 1996 & 33 & 285 & 2006 & 43 & 218 \\
\hline 1967 & 4 & 138 & 1977 & 14 & 63 & 1987 & 24 & 75 & 1997 & 34 & 178 & 2007 & 44 & 135 \\
\hline 1968 & 5 & 79 & 1978 & 15 & 9 & 1988 & 25 & 199 & 1998 & 35 & 153 & 2008 & 45 & 92 \\
\hline 1969 & 6 & 89 & 1979 & 16 & 35 & 1989 & 26 & 47 & 1999 & 36 & 226 & 2009 & 46 & 203 \\
\hline 1970 & 7 & 66 & 1980 & 17 & 15 & 1990 & 27 & 28 & 2000 & 37 & 81 & 2010 & 47 & 437 \\
\hline 1971 & 8 & 84 & 1981 & 18 & 190 & 1991 & 28 & 89 & 2001 & 38 & 238 & 2011 & 48 & 55 \\
\hline 1972 & 9 & 386 & 1982 & 19 & 36 & 1992 & 29 & 195 & 2002 & 39 & 341 & 2012 & 49 & 25 \\
\hline
\end{tabular}

Эту таблицу нужно ежегодно дополнять и проводить повторное моделирование с 1963 г. Статистика лесных пожаров пока имеет малую достоверность. Экологи оценивают площадь пожаров с помощью спутникового мониторинга. В разных источниках информации приводятся сильно различающиеся между собой количественные данные. Поэтому погрешность измерений можно оценивать только сопоставлением данных: для РМЭ она равна 9,1\%.

Итак, погрешность измерений и регистрации количества лесных пожаров на территории РМЭ достигает 10\%. Поэтому и статистическое моделирование [8; 9] нужно проводить не точнее уровня добротности таких исходных данных. Но даже при этом появляются волновые составляющие, которые дают закономерности с очень сильной теснотой связи.

Методику моделирования покажем по ходу выявления биотехнической закономерности от простого уравнения к сложной конструкции с несколькими волновыми составляющими.

Трендовая закономерность. Она дает тенденцию до 1963 г. и после 2012 г. В программной среде типа CurveExpert вначале выявляется (рис. 1) тренд по формуле 


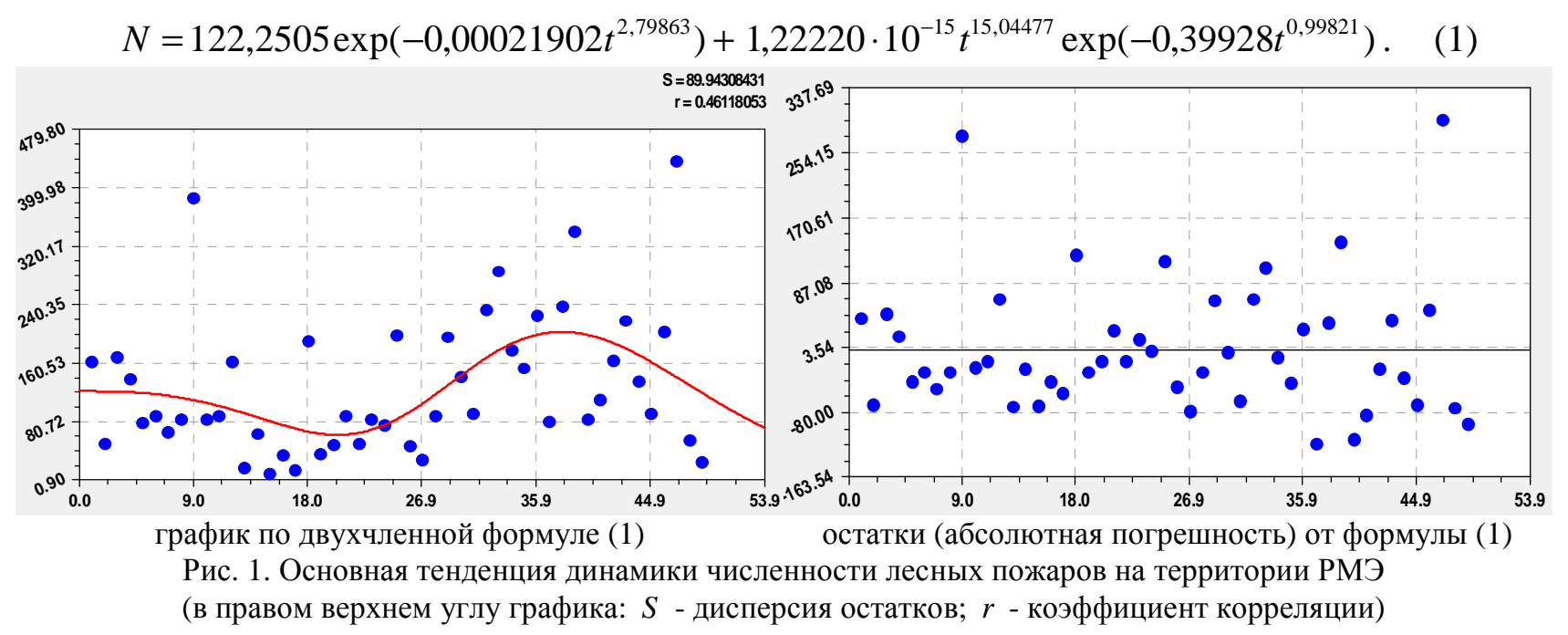

Из первой составляющей формулы (1), являющейся законом экспоненциального спада [38], видно, что в среднестатистическом смысле за 50 лет численность лесных пожаров медленно снижается. Это естественный процесс указывает на то, что качество охраны лесов от пожаров на локальной территории медленно нарастает. Однако за период 1983-2002 гг. наблюдалось стрессовое возбуждение пожаров по второй составляющей формулы (1). Этот биотехнический закон [3] в тренде (1) характеризует антропогенное влияние, то есть влияние системного социально-экономического кризиса страны, который по графику на рисунке 1 нарастал 20 лет с 1983 по 2002 г., а потом в течение 10 лет убывает с 2002 по 2012 г.

Таким образом, в тренде (1) первый член показывает качество лесной службы, а второй член дает характеристику проявления системного кризиса со времен СССР на территории РМЭ. Поэтому тренд (1) сам по себе никакого отношения к солнечной активности не имеет.

Уровни адекватности. Адекватность предыдущего вывода является средней (табл. 2) с коэффициентом корреляции 0,4612. Но по остаткам на рисунке 1 заметно, что точки около линии регрессии по формуле (1) размещаются волнообразно.

Таблица 2 - Уровни адекватности факторных отношений

\begin{tabular}{|c|c|c|c|}
\hline \multirow{2}{*}{$\begin{array}{c}\text { Интервал } \\
\text { коэффициента } \\
\text { корреляции }\end{array}$} & \multicolumn{3}{|c|}{ Характер тесноты связи между факторами } \\
\hline & $\begin{array}{l}\text { существующая } \\
\text { классификация }\end{array}$ & $\begin{array}{c}\text { для технических } \\
\text { экспериментов }\end{array}$ & $\begin{array}{c}\text { уточненная шкала } \\
\text { для лесных пожаров }\end{array}$ \\
\hline 1 & \multirow{5}{*}{ сильная связь } & однозначная & однозначная \\
\hline $0,99 \ldots 1,00$ & & \multirow{3}{*}{ сильнейшая } & почти однозначная \\
\hline $0,95 \ldots 0,99$ & & & сверхсильная \\
\hline $0,90 \ldots 0,95$ & & & сильнейшая \\
\hline $0,7 \ldots 0,9$ & & сильная & сильная \\
\hline $0,5 \ldots 0,7$ & \multirow{2}{*}{ слабая связь } & средняя & средняя \\
\hline $0,3 \ldots 0,5$ & & слабоватая & слабоватая \\
\hline $0,1 \ldots 0,3$ & \multirow{3}{*}{ нет связи } & слабая & слабая \\
\hline $0,0 \ldots 0,1$ & & слабейшая & слабейшая \\
\hline 0 & & нет связи & нет связи \\
\hline
\end{tabular}

И это позволяет дополнительно к тренду (1) идентифицировать параметры у множества асимметричных вейвлет-сигналов [4; 5], то есть совокупности волновых уравнений с пере- 
менными амплитудой и периодом. Последний и может совпадать с параметрами поведения Солнца. Для динамических рядов годичной численности лесных пожаров пришлось ввести еще два уровня адекватности, что было выполнено только при моделировании распределений рядов простых чисел [5] и параметров растущих лесных деревьев и древостоев.

\section{Основная модель динамики.}

После объединения с трендом (рис. 2) получили статистическую модель вида

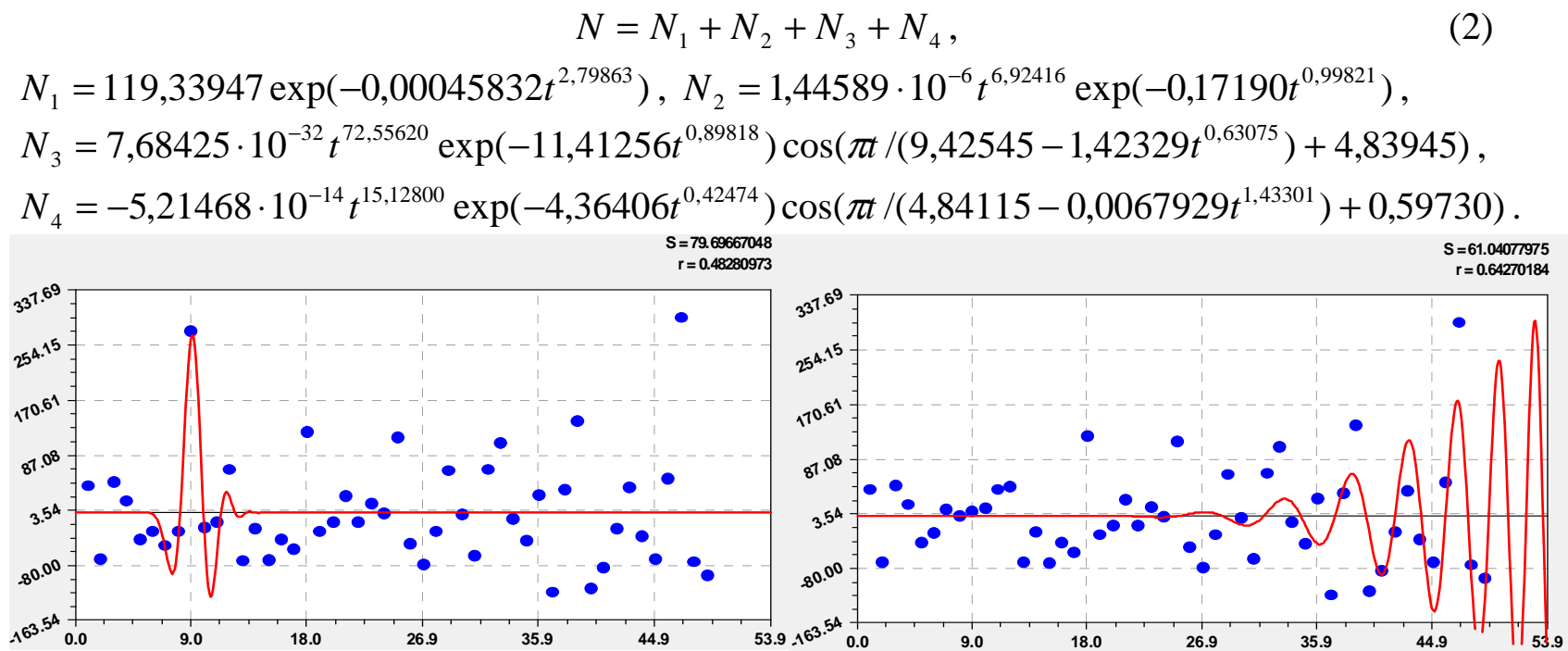

вейвлет-сигнал численности пожаров с пиком в 2002 г.

нарастающее колебание с 1988 г. на будущее

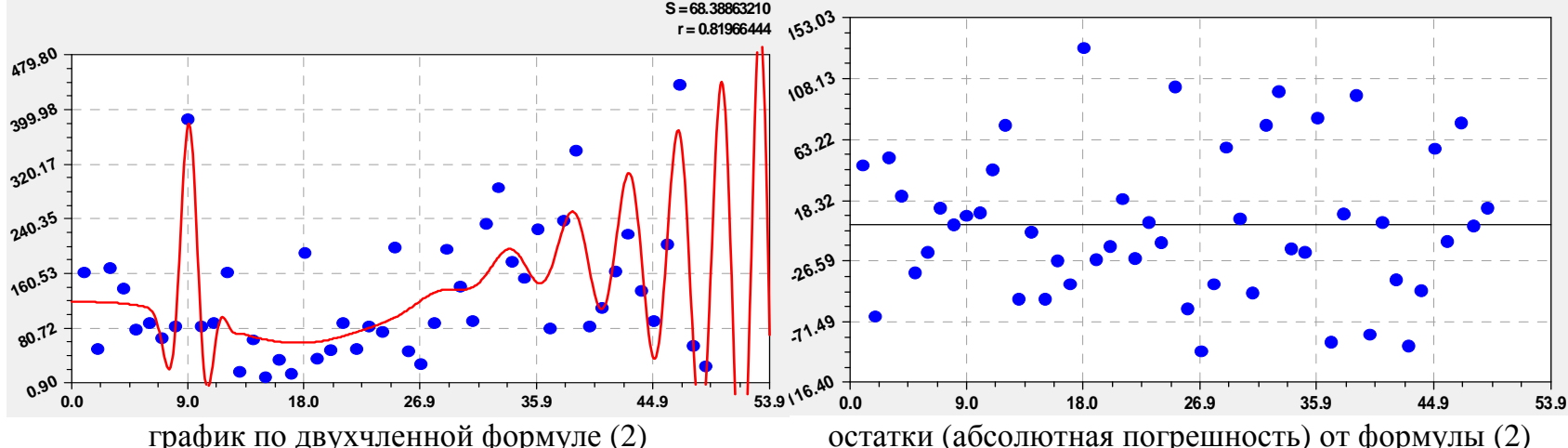

Рис. 2. Основная модель динамики численности лесных пожаров на территории РМЭ

Коэффициент корреляции 0,8197 выше уровня требуемой адекватности 0,7. Уравнение (2) по уровням из таблицы 2 получает сильную тесноту факторной связи. По модели (2) первое колебательное возмущение было в период с 1969 по 1974 год, то есть всего пять лет. Остатки после этой волны (второй график на рисунке 2) почти приблизились к оси абсцисс. При этом амплитуда (половина) резко возросла и затем также резко убавилась. В итоге это колебание ныне имеет только историографическую ценность, поэтому на прогноз численности лесных пожаров на территории РМЭ далее 1985 г. не влияет. Период колебания на 1963 г. был равным $2 \times 9,42545=18,85$ года. С малой вероятностью можно допустить, что когда-то на территории марийского края периодичность скачка в количестве лесных пожаров была 
равна циклу обращения ядра Солнца вокруг своей оси в 22,4 года. Но к 1983 г. этот период равен нулю, поэтому вейвлет имеет антропогенный, а не гелиогенный, характер.

Вторая волна получает прогнозную силу с начальным в 1963 г. периодом $2 \times 4,84115=9,7$ лет. Но до 1987 г. она имела очень малую амплитуду колебания. И только затем резко нарастет по амплитуде, при этом снижая период колебания. Процесс роста численности лесных пожаров имеет аналогию с аварийным разносом двигателя автомобиля. Территория, если не принять кардинальных противопожарных мер, может лишиться всех лесных участков с сильно горючими древостоями. Расчеты полупериода показывают, что второе колебательное возмущение прекратится только к 2060 г.

Таким образом, оба колебания не имеют отношения к циклам солнечной активности.

Продолжение вейвлет-анализа. Остатки от (2) показали, что возможна идентификация последующих волн возмущения в динамике количества лесных пожаров за 50 лет.

Для идентификации закономерностей достаточна конструкция вейвлета типа

$$
y=\sum_{i=1}^{m} y_{i}, y_{i}=a_{1 i} x^{a_{2 i}} \exp \left(-a_{3 i} x^{a_{4 i}}\right) \cos \left(\pi x /\left(a_{5 i}+a_{6 i} x^{a_{7 i}}\right)-a_{8 i}\right) .
$$

где $y$ - показатель (зависимый фактор), $i$ - номер составляющей (3), $m$ - количество составляющих, $x$ - объясняющая переменная (влияющий фактор), $a_{1} \ldots a_{10}$ - параметры модели (3), принимающие числовые значения в процессе структурно-параметрической идентификации.

Параметры модели можно записать в матричной форме (табл. 3). При этом тренд есть волна с полупериодом, многократно превышающим интервал измерений.

Короткомерные семь вейвлет-сигналов, находящиеся в интервале времени 50 лет и объединенные по возможностям программной среды в три подгруппы, даны на рисунке 3.

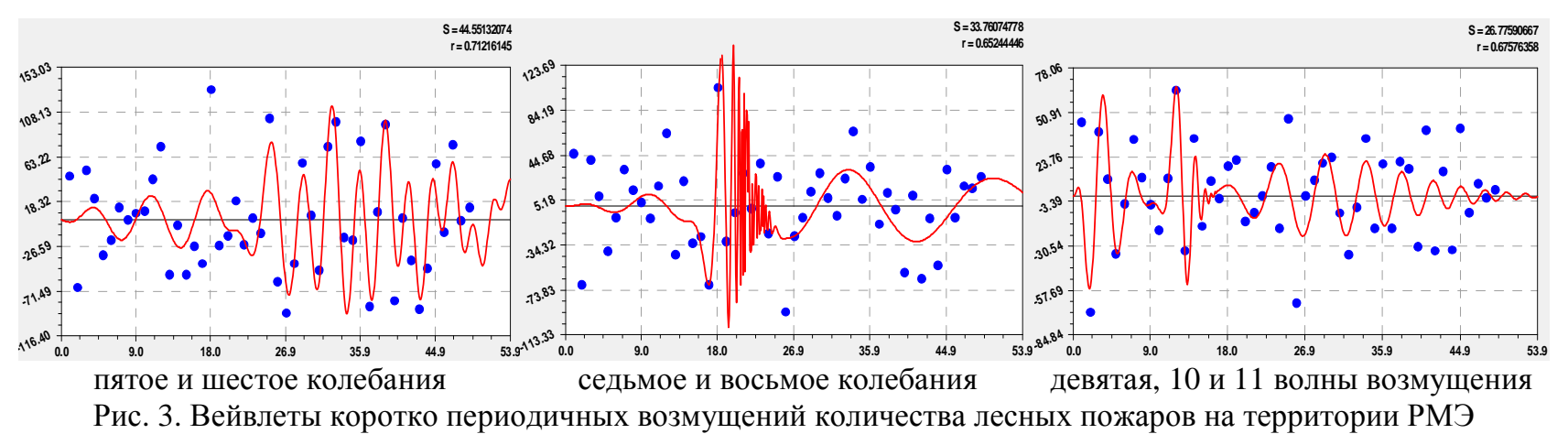

Максимальная относительная погрешность остатков после 33-го члена общей статистической модели равна 0,56\% для 1978 г. Такая малая погрешность указывает на добротность исходных данных динамического ряда.

Мезоколебания. Период в 50 лет по девяти колебаниям делится на две части с границей при $t=22-25$ лет, т.е. на этапы до 1985 г. и после 1988 г. Как видно из графиков на рисунке 3, в советские времена колебания были короткими, но значительными по амплитуде. На вто- 
ром этапе с 1988 г. волновые распределения характеризуются еще и значительной продолжительностью. Особенно в будущем опасна вторая волна возмущения по формуле (2).

Девять колебаний по составляющим № 12-20 показаны на рисунке 4.

Таблица 3. Параметры общего уравнения динамики количества локальных лесных пожаров

\begin{tabular}{|c|c|c|c|c|c|c|c|c|c|}
\hline \multirow{3}{*}{$\begin{array}{c}\text { Ho- } \\
\text { мep } \\
i\end{array}$} & \multicolumn{8}{|c|}{ Вейвлет $y_{i}=a_{1 i} x^{a_{2 i}} \exp \left(-a_{3 i} x^{a_{4 i}}\right) \cos \left(\pi x /\left(a_{5 i}+a_{6 i} x^{a_{7 i}}\right)-a_{8 i}\right)$} & \multirow{3}{*}{$\begin{array}{c}\text { Коэфф. } \\
\text { корр. } \\
r\end{array}$} \\
\hline & \multicolumn{4}{|c|}{ амплитуда (половина) колебания } & \multicolumn{3}{|c|}{ полупериод колебания } & \multirow{2}{*}{$\frac{\text { сдвиГ }}{a_{8 i}}$} & \\
\hline & $a_{1 i}$ & $a_{2 i}$ & $a_{3 i}$ & $a_{4 i}$ & $a_{5 i}$ & $a_{6 i}$ & $a_{7 i}$ & & \\
\hline \multicolumn{10}{|c|}{ Общая статистическая модель в виде тренда с двумя сильными мегаколебаниями поведения населения } \\
\hline 1 & 119,33947 & 0 & 0,00045832 & 2,79863 & 0 & 0 & 0 & 0 & \multirow{4}{*}{0,8197} \\
\hline 2 & $1,44589 \mathrm{e}-6$ & 6,92416 & 0,17190 & 0,99821 & 0 & 0 & 0 & 0 & \\
\hline 3 & $7,68425 \mathrm{e}-32$ & 72,55620 & 11,41256 & 0,89818 & 9,42545 & $-1,42329$ & 0,63075 & $-4,839$ & \\
\hline 4 & $-5,21468 \mathrm{e}-14$ & 15,12800 & 4,36406 & 0,42474 & & $-0,0067929$ & 1,43301 & $-0,5$ & \\
\hline \multicolumn{10}{|c|}{ Короткомерные средние по амплитуде вейвлет-сигналы макроколебания численности лесных пожаров } \\
\hline 5 & 66986,327 & 2,70261 & 9.85601 & 0,15762 & 3,57109 & 0 & 0 & $-3,18428$ & \multirow{2}{*}{0,7122} \\
\hline 6 & $4,90039 \mathrm{e}-17$ & 36,29153 & 19,14102 & 0,42602 & 3,71042 & $-0,13513$ & 0,66273 & $-0,57666$ & \\
\hline 7 & 3,63 & 88,24747 & 4,6 & 1 & 39,10 & $-1,76$ & 1 & & \multirow{2}{*}{0,6524} \\
\hline 8 & $-0,73$ & 1,16789 & $1,13866 \mathrm{e}-5$ & 2,91804 & 2,90432 & 0,13093 & 0,79788 & 5,00160 & \\
\hline 9 & 68 & 2,41694 & & 1 & 1,7 & 0 & 0 & 0 & \multirow{3}{*}{0,6758} \\
\hline 10 & $-2,02491 e-59$ & 92,36868 & 7,513 & 1 & 10,22157 & $-0,20384$ & 1,33915 & $-1,30043$ & \\
\hline 11 & $-2,94262 \mathrm{e}-13$ & 13,85771 & 0,59207 & 0,95115 & 3,72366 & $-0,00072908$ & 1,91588 & $-0,057007$ & \\
\hline \multicolumn{10}{|c|}{ Длинномерные мезоколебания численности лесных пожаров на локальной территории } \\
\hline 12 & $-9,58505$ & 0 & $-0,00$ & 1 & $-0,64111$ & 1,27158 & 0,027792 & 1,27198 & \multirow{2}{*}{0,5444} \\
\hline 13 & $-32522,329$ & 0 & 1,10147 & 1 & 1,00090 & 0 & 0 & $-1,56976$ & \\
\hline \multicolumn{10}{|c|}{ Мезоколебания в виде вейвлет-сигналов о динамике численности лесных пожаров на территории РМЭ } \\
\hline 14 & -710 & 5,45544 & & & 3,02059 & 0 & 0 & 49 & 0,2727 \\
\hline 15 & 0,00 & 9353 & & & 72 & 065768 & 87771 & $-1,55$ & 279 \\
\hline 16 & $-1,6$ & 3 & & & & & & & \\
\hline 17 & 7,45 & 52,76551 & 0,5 & 1, & & 80 & 0 & $-5,5$ & 742 \\
\hline 18 & -48e-6 & 6,39989 & 0,072984 & 1,47635 & 1,86359 & 0,00016623 & 2,14254 & 0,715 & 783 \\
\hline \multicolumn{10}{|c|}{ Импульсные мезоколебания антропогенного влияния на количество лесных пожаров } \\
\hline 19 & $-3,45567 \mathrm{e}-129$ & 112,73801 & 3,2 & 0,97008 & 1,29870 & $-0,0051550$ & 0,90655 & 0,82484 & 0,7905 \\
\hline 20 & $-0,0012547$ & 4,19495 & 0,0010374 & 2,51064 & 0,91814 & 0,00027857 & 1,67696 & 1,07178 & 624 \\
\hline \multicolumn{10}{|c|}{ Микроколебания в виде длинных волн динамики возмущения численности лесных пожаров } \\
\hline 21 & 10,28746 & 0 & 0,068439 & 1 & 58,55825 & $-1,27230$ & 1 & 1,67677 & 441 \\
\hline 22 & & 0 & 47 & 1 & 73 & 0,0010287 & 2,07926 & 2,39 & 0,5265 \\
\hline 23 & 0,30286 & 0 & $-0,035605$ & 1 & 3,50130 & 0,0061667 & 1 & 0,41809 & 0,4209 \\
\hline \multicolumn{10}{|c|}{ Микрокороткомерные вейвлет-сигналы об антропогенном поведении в отношении к лесным пожарам } \\
\hline 24 & & 0,35553 & 0,063199 & 1 & $-0,065745$ & 0,39918 & 0,35548 & 4,00313 & 0,4347 \\
\hline 25 & $-7,20$ & 6,91013 & 2,98928 & 0,44258 & 0,4 & 0,17551 & 0,39897 & 5,57913 & 0,7533 \\
\hline 26 & 00 & 0,25707 & 0,00017005 & 2,14277 & 199 & 0,0080530 & 1,17677 & 1,80924 & 0,3178 \\
\hline 27 & $-1,99176 e-57$ & 48,64450 & 1,24850 & 0,99104 & 0,58 & 0,012897 & 0,85045 & 0,32734 & 0,7318 \\
\hline 28 & $-0,035010$ & 3,63071 & 0,57 & 0,95239 & 1,79949 & $-0,0015890$ & 1,67514 & 1,95361 & 0,5948 \\
\hline 29 & & 0,19362 & $1,28367 \mathrm{e}-5$ & 2,80588 & 3,17680 & $-0,00065677$ & 1,31733 & $-1,87754$ & 0,5278 \\
\hline 30 & $4,11788 \mathrm{e}-7$ & 26,74821 & 7,18029 & 0,81538 & 1,08407 & $-0,0067981$ & 0,98302 & 0,72475 & 0,3933 \\
\hline 31 & $1,49741 \mathrm{e}-9$ & 8,80569 & 0,57154 & 0,84678 & 1,58329 & 0,00050219 & 1,46044 & 3,03251 & 0,7670 \\
\hline 32 & $-2,67238 \mathrm{e}-7$ & 11,11165 & 4,08933 & 0,52195 & 1,91371 & 0,0083175 & 0,89274 & 2,89823 & 0,7670 \\
\hline \multicolumn{10}{|c|}{ Сверхдлинные микроволны колебательного возмущения населения } \\
\hline 33 & $-0,27972$ & 0 & 0,022623 & 1 & $-4,46202$ & 6,03654 & 0,31842 & 3,19208 & 0,7209 \\
\hline
\end{tabular}

Длинные волны № 12 и 13 остаются в прошлом. Поэтому эколого-экономическая оценка должна вестись по новой методологии, с учетом историографического анализа [6]. 


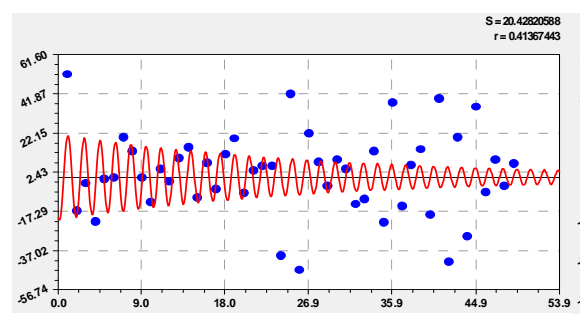

12-я составляющая модели

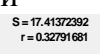

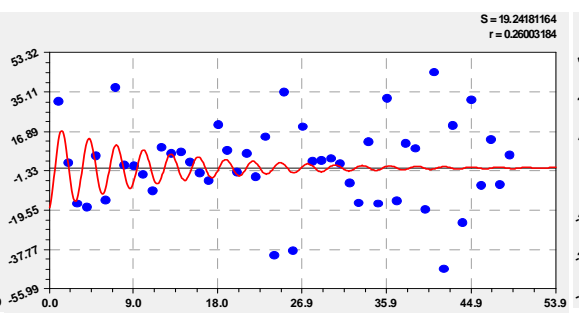

13-я составляющая модели $\mathrm{S}=17.02530374$
$\mathrm{r}=0.19152343$

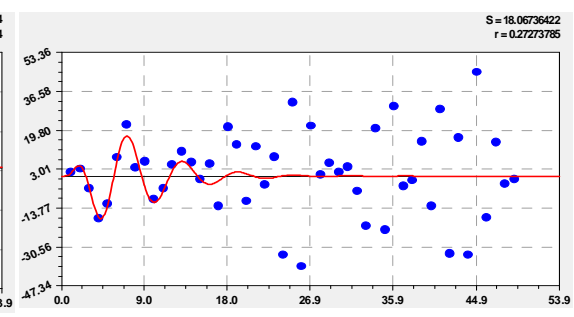

14-я составляющая модели

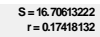

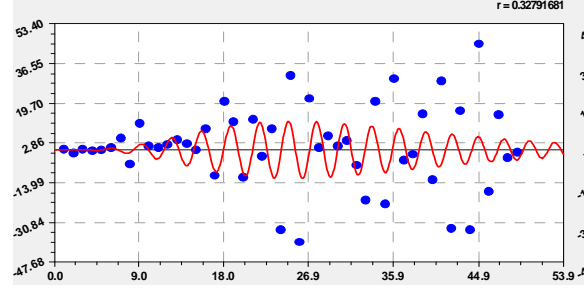

15-я составляющая модели

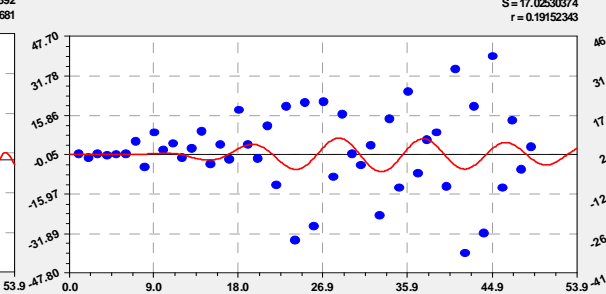

16-я составляющая модели $S=16.59592421$
$r=0.07333438$

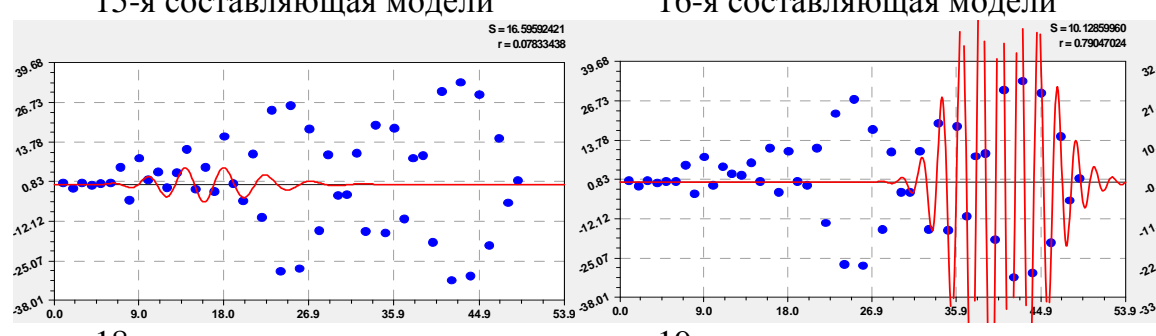

18-я составляющая модели

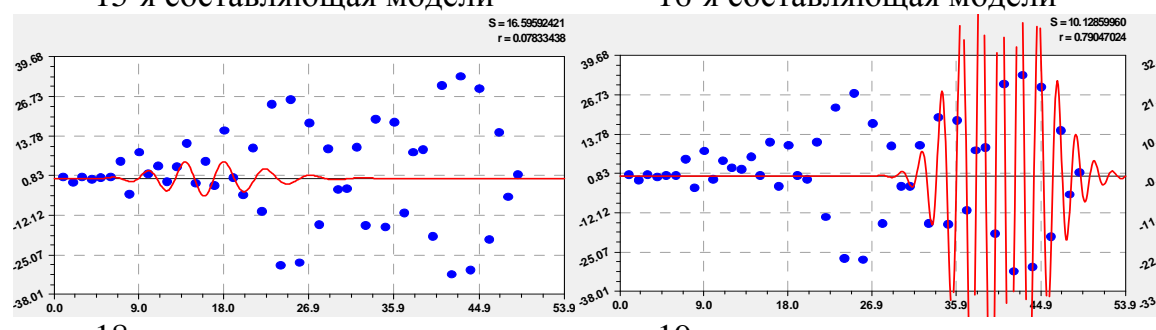

19-я составляющая модели

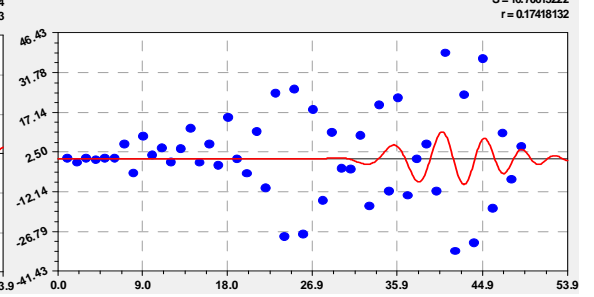

17-я составляющая модели

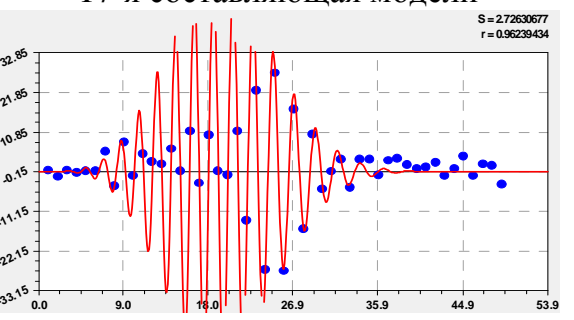

20-я составляющая модели

Рис. 4. Вейвлеты динамического мезовозмущения количества лесных пожаров на территории РМЭ

Два импульсных мезоколебания по графикам на рисунке 4 выделяют подэтапы 1970-1999 и 1993-2015 гг., адекватность этих вейвлет-сигналов из прошлого равна 0,7905 и 0,9624. С вероятностью 79,05\% кризисное (отрицательный знак перед составляющей) поведение людей в отношении к лесным пожарам с 2016 г. должно коренным образом измениться.

Микроколебания. Они опасны на будущее тем, что могут разрастись до макроуровня.

На рисунке 5 даны графики характерных по таблице 3 микроволновых закономерностей.

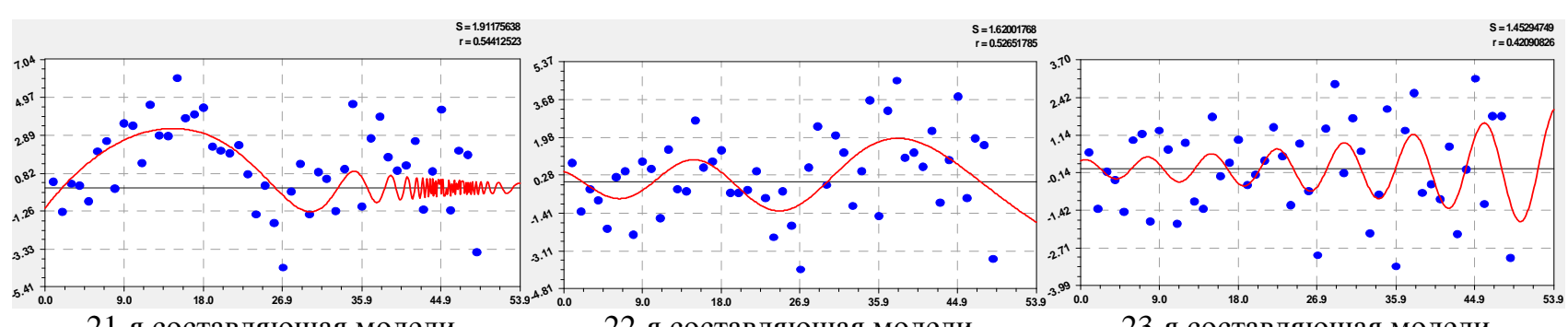

21-я составляющая модели $\mathrm{S}=0.80800267$
$\mathrm{r}=0.7532800$
$22-9$ составляющая модели

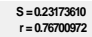

23-я составляющая модели

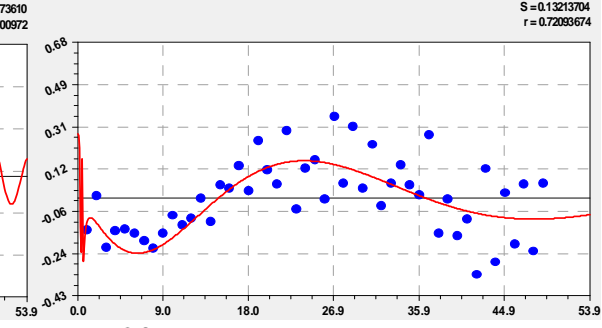

20-я составляющая модели

25-я составляющая модели

Рис. 5. Вейвлеты динамического микровозмущения количества лесных пожаров на территории РМЭ

Поэтому нужно ежегодное итеративное моделирование модели динамики. При этом 21-я волна показывает докризисное поведение: в 1990 году было минимальное количество - всего 
28 лесных пожаров. Аналогия с затишьем перед бурей: хаос хозяйствования привел к увеличению количества лесных пожаров. И нарастают на будущее 22-я и 23-я составляющие, но еще долго будет значимой 25-я волна, хотя уходят в историю 31-й и 32-й члены модели. Медленно и долго уходит со сцены лесных пожаров доктрина 33 начала 60-х годов XX века.

Выводы. Чтобы повысить точность прогнозирования, нужно ежегодно проводить повторную идентификацию вышеприведенных формул с дополнением количества лесных пожаров, происходивших за 2013 год и так далее. Это и станет итерационным статистическим моделированием по ежегодно дополняемым статистическим данным.

Такая методика позволит гораздо точнее прогнозировать численность лесных пожаров на следующий год и тем самым заранее подготовиться к пожароопасному сезону.

Основная доля лесных пожаров происходит из-за поведения населения. На втором месте по значимости находятся грозы и молнии. Поэтому изменение амплитуды колебания по уравнениям из таблицы 3 возможно только после реализации мер по профилактике будущих лесных пожаров, снижению накапливающихся объемов лесных горючих материалов и повышению экологического сознания у населения и самих лесохозяйственников.

\section{Список литературы}

1. Каткова Т.Е. Прогноз периодов повышенной горимости лесов Республики Марий Эл на основе периодических изменений солнечной активности // Актуальные проблемы лесного комплекса / под ред. Е.А. Памфилова : сб. науч. тр. по итогам междунар. науч.-техн. конф. Вып. 15. - Брянск : БГИТА, 2006. - С. 29-31.

2. Каткова Т.Е. Солнечная активность и периоды повышенной горимости лесов Республик Марий Эл и Коми // Наука в условиях современ. : сб. ст. студ., асп., докторантов и проф.преп. состава по итогам НИР МарГТУ в 2006 г. - Йошкар-Ола : МарГТУ, 2006. - С. 15-18.

3. Мазуркин П.М. Биотехнический закон и виды факторных связей // Успехи современного естествознания. - 2009. - № 9. - С. 152-156.

4. Мазуркин П.М. Вейвлет-анализ ряда простых чисел // Фундаментальные исследования. 2011. - № 12. - C. 568-575.

5. Мазуркин П.М. Закономерности простых чисел. - Германия : Palmarium Academic Publishing, 2012. - $280 \mathrm{c}$.

6. Мазуркин П.М. Историографический анализ динамики населения России // Международный журнал прикладных и фундаментальных исследований. - 2009. - № 5. - С. 56-69. 
7. Мазуркин П.М., Блинова К.С. Активность Солнца и годичная динамика лесных пожаров на особо охраняемой территории // Успехи соврем. естествознания. - 2013. - № 1. - С. 102107.

8. Мазуркин П.М., Порядина О.В. Эконометрическое моделирование : практикум. - ЙошкарОла : МарГТУ, 2009. - 204 с.

9. Мазуркин П.М., Филонов А.С. Математическое моделирование. Идентификация однофакторных статистических закономерностей : учеб. пособ. - Йошкар-Ола : МарГТУ, 2006. - 292 c.

10. Пожар от спички. В республике горят леса // АИФ в Марий Эл. Региональное приложение. - 2012. - № 29 (482). 18-24 июля.

\section{Рецензенты:}

Салихов М.Г., д.т.н., профессор, кафедра автомобильных дорог ФГБОУ ВПО «Поволжский государственный технологический университет», г. Йошкар-Ола.

Колупаев Б.И., д.б.н., профессор, профессор кафедры водных ресурсов ФГБОУ ВПО «Поволжский государственный технологический университет», г. Йошкар-Ола. 